\title{
Elasto - plastic modelling of the behaviour of non - active clays under chemo - mechanical actions
}

\author{
Guido Musso ${ }^{1, *}$, Giulia Scelsi ${ }^{2}$, and Gabriele Della Vecchia ${ }^{2}$ \\ ${ }^{1}$ DISEG, Politecnico di Torino, Corso Duca degli Abruzzi, 10129 Torino, Italy \\ ${ }^{2}$ DICA, Politecnico di Milano, Piazza Leonardo da Vinci, 32, 20133 Milano, Italy
}

\begin{abstract}
Environmental variables such as temperature, matric suction and pore fluid composition are well known to influence the hydro-mechanical behavior of clays and shales. The type and the relevance of this influence depends on the mineralogical composition and on the fabric of the material. Soil activity is an engineering proxy for mineralogical composition which can be used for a preliminary characterization of the expected type of behaviour under chemical actions, if those do not imply very significant cation exchange or $\mathrm{pH}$ variations. Very large chemo-mechanical effects occur in highly active soils used in engineering works such as barriers for nuclear waste or landfills, however concentration changes also impact on the mechanical behavior of non - active soils and rocks, such as illitic or natural blends of clays. Such materials are widely distributed in nature and their mechanical response upon chemical changes can be problematic in many cases. Examples of engineering relevance include vast slope instabilities promoted by fabric changes due to desalinization in Scandinavian quick clays, and instability or convergence issues for boreholes drilled in shales exposed to muds with a different chemical composition from the one of the pore fluid. An elastoplastic model is formulated to simulate the volumetric behaviour of such materials along chemical and mechanical loads. In addition to the parameters of the Modified Cam Clay, it requires defining the dependency of the elasto-plastic compliance and reference void ratio on pore fluid salinity. The model performs well against experiments from literature where complex chemo-mechanical histories were imposed.
\end{abstract}

\section{Introduction}

The dependency of the mechanical response of soils with a significant clay fraction on the chemical composition of the pore fluid is well known in the scientific literature. This dependency stems from physico-chemical interaction forces exchanged between clay particles. In soil suspensions, interaction forces are both attractive (mainly van der Waals forces) and repulsive (mainly electrostatic forces). The strength and type of interaction is controlled by the mineralogy and the dimension of the particles. van der Waals forces decrease with the particle radii, while they have a very small dependency on the fluid. Electrostatic forces are due to the charge deficiency of the clay mineral, and they increase with the particle charge density and surface. The interaction forces are then expected to grow with the specific surface (i.e. particle surface to volume ratio) and the cation exchange capacity. As for common clay minerals (see [1] for their main properties), the largest chemical effects are expected for montmorillonite, followed by illite and kaolinite, respectively. However, other factors linked to the mineralogy play an important role, e.g. (i) $\mathrm{pH}$ controls the superficial charge of kaolinite; (ii) the size and charge of the cation in the pore fluid controls the effectiveness of the bonds between different mineral layers in montmorillonite minerals.
Accounting for physico-chemical forces alone might allow modelling the behaviour of regular packages of clays (e.g. suspensions), whereas the behaviour of real soils is further complicated by mineral heterogeneity, fabric and by the effective stress. A preliminary evaluation of the sensitivity of a soil to pore fluid chemistry can be made by evaluating how the latter impacts on the liquid limit [2]. An increase in ionic concentration of water solutions (i.e. salinity) normally causes a decrease of the liquid limit, which is small in the case of illite, it is moderate for kaolin and it is very large for bentonite. The increase of the dielectric constant of the pore fluid leads instead to an increase in the liquid limit of illite and bentonite, and to a decrease of the liquid limit of kaolinite.

For engineering purposes, when limiting the analysis to the effects of salinity, it might be convenient referring to a simpler clay classification than the one based on mineralogical analyses, which are expensive and not routinely run in engineering activities. It is here proposed to refer to the activity index $A$ (the ratio between the plasticity index and the fraction of particles with equivalent diameter $d \leq 2 \mu \mathrm{m},[1])$. Besides allowing taking into account the contribution of different minerals in a simplified manner, activity has the advantage of accounting for the role of particle size on the dependency of the liquid limit on the salinity. It is customary to define

\footnotetext{
* Corresponding author: guido.musso@polito.it
} 
as active clays those with $\mathrm{A}>1.25$, normal those with $0.75 \leq \mathrm{A} \leq 1.25$ and inactive clays those with $\mathrm{A}<075$.

The mechanical behaviour of active clays is strongly influenced by the pore fluid chemistry. Experimental evidences show that the elastic and elasto-plastic compliances of bentonite decreases noticeably with the salinity, both for remoulded samples prepared from slurry [3] and for statically compacted samples saturated with different solutions [4]. Bentonite samples also show very large volume strains when the concentrations of their saturating pore fluid changes under a constant effective stress $[3,5]$.

On the other hand, the pore fluid salinity only has a small influence on the compression behaviour of normal or inactive soils, such as kaolinite [6], illite [7, 8] and natural clays of mixed composition [9, 10]. However, these soils still develop important volume strains when exposed to salinity changes under constant stress $[8,10]$. Although less dramatic than those of bentonites, such strains can lead to large settlements [11] and, in the case of Norwegian 'quick' clays, they can also be related to microstructural changes which ultimately lead to impressive slope instabilities [12].

Proper constitutive modelling of the chemomechanical behaviour of soils is important for several applications, spanning from classical geotechnical systems (e.g. slope instability, foundation settlements), geoenvironmental processes (landfills, polluted sites) and energy geotechnics problems (wellbore stability, enhanced oil recovery, $\mathrm{CO}_{2}$ sequestration). In the literature, constitutive modelling has been pursued in the frame of hardening elasto-plasticity, among others in [13, $14,15,8,16]$. These models rely, in general, on experimental evidences about high activity clays. The aim of the present work is to propose a simple model tailored on the physical evidences of the chemo-mechanical behaviour of normal and inactive clays, which in the following are simply defined as 'non - active clays'. After describing model assumptions and equations, numerical predictions are compared to experimental results for two different non - active clays from the literature.

\section{Model description}

The model is formulated in the context of the theory of elasto-plasticity with generalized hardening [17] and it is based on the assumptions discussed in the following.

\subsection{Stress variables}

Two independent stress variables are introduced, one for mechanical loading and the other for chemical loading. The first one is the Terzaghi effective stress tensor, whose components $\sigma_{\text {ij }}^{\prime}$ are defined as:

$$
\sigma_{i j}^{\prime}=\sigma_{i j}-u \delta_{i j}
$$

where $\sigma_{i j}$ is the total stress, $u$ is the fluid pressure and $\delta_{\mathrm{ij}}$ is the Kronecker's delta.

The chemical stress variable is osmotic suction $\pi$. Its choice is justified by considering that, for low to medium activity soils, cation exchange phenomena do not play any significant role on the mechanical behaviour, and thus accounting for the type of cation in solution is not required. This assumption is not realistic in the case of kaolin soils undergoing $\mathrm{pH}$ changes, which are out of scope here. Osmotic suction depends on the chemical activity of the components in solution and, at low concentrations, it can be described by the van't Hoff equation:

$$
\pi=i c R T
$$

where $i$ is the number of dissolved species (e.g. 2 for $\mathrm{NaCl}$ and 3 for $\mathrm{CaCl}_{2}$ ), $c$ is the ion concentration of the electrolyte, $R$ is the universal gas constant $\left(8.31 \mathrm{~J} \mathrm{~mol}^{-1} \mathrm{~K}^{-1}\right)$ and $T$ is the absolute temperature $(\mathrm{K})$.

\subsection{Elastic behaviour}

Elastic volumetric strain increments are split into two contributions, one due to mechanical loading and the other due to osmotic suction changes. The mechanical contribution is described by the classical logarithmic compliance adopted in critical state soil mechanics. A similar expression is assumed to hold for increments in osmotic suction. The following equation gives the elastic volumetric strain increment strain $\dot{\varepsilon}_{v}^{e}$

$$
\dot{\varepsilon}_{v}^{e}=\dot{\varepsilon}_{v, m e c}^{e}+\dot{\varepsilon}_{v, c h}^{e}=\frac{\kappa}{v} \frac{\dot{p}^{\prime}}{p^{\prime}}+\frac{\kappa_{\pi}}{v} \frac{\dot{\pi}}{\pi}
$$

where $v$ is the specific volume, $\kappa$ is the elastic logarithmic mechanical compliance, $p^{\prime}$ is the mean stress, $\kappa_{\pi}$ is the elastic logarithmic chemical compliance.

Chemical changes are assumed to cause only isotropic strains, so that the chemical component of the deviatoric strain increment is neglected. The increment of elastic deviatoric strain $\dot{\varepsilon}_{s}^{e}$ is then:

$$
\dot{\varepsilon}_{s}^{e}=\frac{1}{3 G} \dot{q}
$$

with $G$ is the shear modulus and $q$ is the deviatoric stress.

\subsection{Elastic-plastic behaviour}

\subsubsection{Isotropic paths}

In the compression plane, the elasto-plastic states of saturated clays rest on the Normal Compression Line (NCL), which defines the highest void ratio that the soil is able to sustain under a given mean effective stress and for the current fabric. As it contributes to the interaction forces between the particles, osmotic suction impacts on soil fabric and the NCL is then dependent on pore fluid chemistry. It is then anticipated that different NCLs can exist depending on the process that lead to soil formation and on the pore fluid chemistry. As a consequence, both the parameters that identify the NCL in the compression plane (i.e. the slope on the semi-logarithmic plane $\lambda$ and 
the specific volume $N$ for a reference mean effective stress $p_{r}^{\prime}$ ) may change with $\pi$ and cannot be considered as constants for a given soil. In the following, the variables $\mathrm{N}_{0}$ and $\lambda_{0}$ will be associated to a specimen saturated with distilled water, while the variables $\mathrm{N}_{\mathrm{c}}$ and $\lambda_{\mathrm{c}}$ will be associated to a specimen saturated with a saline solution with osmotic suction $\pi$.

In the context of constitutive modelling, identifying a dependency of the NCL on $\pi$ allows identifying the dependence of preconsolidation pressure on pore fluid salinity. In other words, a link can be deduced between the yield mean effective stress for the material saturated with distilled water $p^{\prime}{ }_{0}$, and the yield mean effective stress for the material saturated with a saline solution of osmotic suction $\pi, p^{\prime}{ }_{\mathrm{c}}(\pi)$. To do so, one can consider the effects of two different loading paths, namely LPI and LPII, represented in the stress plane $\left(p^{\prime}, \pi\right)$ in Figure 1 and in compression plane $\left(v, \ln p^{\prime}\right)$ in Figure 2.

LPI is a loading path where a normally consolidated sample, saturated with a very diluted solution $\left(\pi=\pi_{r e f}=1 \mathrm{kPa}\right)$ is prepared at $p_{\mathrm{r}}^{\prime}=1 \mathrm{kPa}$. Firstly, it is loaded in elasto-plastic condition up to $p^{\prime} 0$ (point A). Then, at constant mean effective stress, osmotic suction is increased up to $\pi=\pi_{\mathrm{B}}$ : according to eq. (3), the increase in osmotic suction causes positive elastic volumetric strain and the specific volume reduces (path $\mathrm{AB}$ in Figure 2 ). The mechanical stress is then increased again at constant osmotic suction: since elasto-plastic strains take place only when moving along the NCL, this volume contraction will be elastic until the mean stress will be $p^{\prime}=p_{c}^{\prime}$, corresponding to a specific volume $v=v_{c}$ (point $\mathrm{C}$ in Figure 2). By further increasing the mechanical stress at constant osmotic suction, the soil state will move along the NCL characteristic of the osmotic suction $\pi=\pi_{\mathrm{B}}$. The expression which relates $p_{c}^{\prime}$ with $p^{\prime}{ }_{0}$ is obtained by considering that point $\mathrm{C}$ can be reached also by another loading path, corresponding to a mechanical load at constant osmotic suction (LPII). This path, representative of a sample which has the same fabric of the sample at point C (see LPI) and for which the osmotic suction remains constant, corresponds in the compression plane to the $\operatorname{NCL}\left(\pi_{\mathrm{B}}\right)$ between $p^{\prime}=p^{\prime}{ }_{\mathrm{r}}$ and $p^{\prime}=p^{\prime}$.

Along LPI, the specific volume $v_{c}$ is evaluated as:

$$
v_{C}=N_{0}-\lambda_{o} \ln \left(\frac{p_{0}^{\prime}}{p^{\prime}{ }_{r}}\right)+\Delta v^{c h}-\kappa \ln \left(\frac{p_{c}^{\prime}}{p^{\prime}{ }_{0}}\right)
$$

where $\Delta v^{c h}$ is the change in specific volume due to the increase in $\pi$ between $\mathrm{A}$ and $\mathrm{B}$, which is assumed to be elastic. According to eq. 3 it can be calculated as is:

$$
\Delta v^{c h}=-\kappa_{\pi} \ln \left(\frac{\pi}{\pi_{r e f}}\right)
$$

Along LPII, $v_{c}$ can be determined as:

$$
v_{C}=N_{c}-\lambda_{c} \ln \left(\frac{p^{\prime}{ }_{c}}{p^{\prime}{ }_{r}}\right)
$$

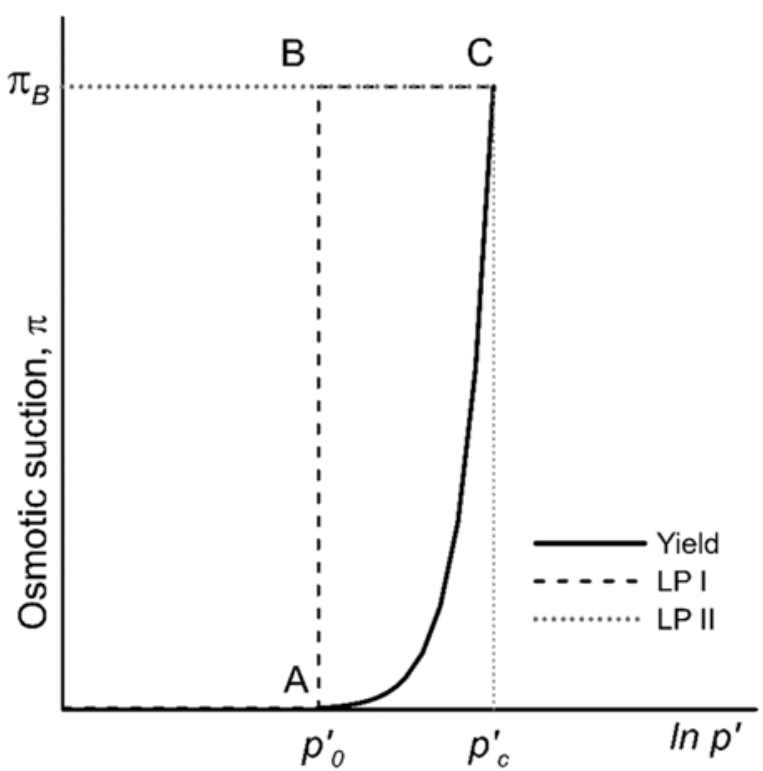

Fig. 1. Loading paths and yield surface in the $\left(p^{\prime}, \pi\right)$ plane.

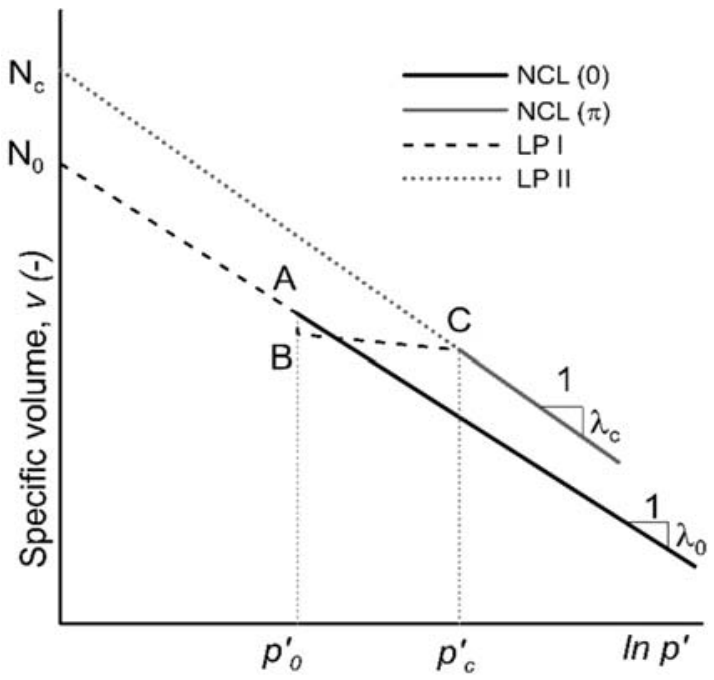

Fig. 2. Normal compression lines for two different osmotic suctions and Loading Paths

By introducing eq. (6) in eq. (5) and equating with eq. (7) it follows:

$$
\frac{p_{c}^{\prime}}{p_{0}^{\prime}}=\left(\frac{p_{0}^{\prime}}{p_{r}^{\prime}}\right)^{\frac{\lambda_{0}-\lambda_{c}}{\lambda_{c}-\kappa}} \cdot \exp ^{\frac{N_{c}-N_{0}}{\lambda_{c}-\kappa}} \cdot\left(\frac{\pi}{\pi_{r e f}}\right)^{\frac{\kappa_{\pi}}{\left(\lambda_{c}-\kappa\right)}}
$$

Eq. (8) provides the expression of the yield function in the $\left(p^{\prime}, \pi\right)$ plane, which is represented in Fig. 1 assuming that both $N_{\mathrm{c}}$ and $\lambda_{\mathrm{c}}$ are logarithmic functions of $\pi$.

The mathematical derivation of this expression is similar to the one of the Loading Collapse (LC) curve of the BBM model for unsaturated soils [18] and it also plays an analogous role in the elastoplastic modelling of the soil behaviour. However, the LC and eq. 8 account for different physical processes (LC for capillarity and eq. 8 
for sensitivity to pore fluid chemistry) and therefore one is not interchangeable with the other.

Note that the right-hand side of equation 8 is the product of three terms: three different aspects thus explain the dependency of the yield stress on osmotic suction. These are: (1) the dependency of the elastoplastic compliance on osmotic suction; (2) the variation of parameter $N$ with osmotic suction; (3) the value of osmotic suction itself. These three factors might have different relevance in different soils, depending on their composition and original fabric. As discussed in Section 1 , the elasto-plastic compliance of non-active clays has a very limited dependency on osmotic suction, thus the first term of equation 8 is very likely to be close to one. Term (2) would be equal to one when there is no dependency of the NCL position on $\pi\left(N_{\mathrm{c}}=N_{0}\right)$. In general, a slight dependence of $N$ on osmotic suction is expected also for non-active clays. However, even when the variation of $N$ and $\lambda$ with osmotic suction is negligible, a dependency of the yield stress $p_{c}{ }_{c}$ on osmotic suction still exists because of the third term of equation 8 .

\subsubsection{Axis symmetric paths}

The expression in eq. (8) gives the mean yield stress $p^{\prime}$ c evolution with osmotic suction under isotropic loading. Extension to more general axis-symmetric conditions is made through the usual expression of the yield surface $(f=0)$ of the Modified Cam Clay model:

$$
f\left(p^{\prime}, q, p_{c}^{\prime}\right)=\frac{q^{2}}{M^{2}}+p^{\prime}\left(p^{\prime}-p_{c}^{\prime}\right)
$$

where $q$ is the deviatoric stress, $M$ is the slope of the Critical State Line in the $\left(p^{\prime}, q\right)$ plane and $p_{c}{ }_{c}$ is given by eq. (8).

The same hardening law of the Modified Cam Clay model is used for the yield mean stress for distilled water as pore fluid, $p^{\prime}{ }_{0}$ :

$$
\dot{\varepsilon}_{v}^{p l}=\frac{\lambda_{0}-\kappa}{v_{0}} \frac{\dot{p}_{0}^{\prime}}{p_{0}^{\prime}}
$$

The formulation is closed by assuming an associated flow rule.

\section{Simulation of chemo-mechanical tests from the literature}

An explicit Runge Kutta stress point algorithm has been implemented in Matlab ${ }^{\circledR}$ to integrate the constitutive equations presented in Section 2. A modified Bardet and Choucair method has been implemented to apply the relevant chemo-mechanical conditions at the representative elementary volume level $[19,20]$. Model predictions were validated against literature results from two different non active clays.

\subsection{Mechanical test with osmotic suction increase under constant stress}

The first simulations refer to [8], which performed oedometer compression tests on an illitic clay (liquid limit $\mathrm{W}_{\mathrm{L}}=54 \%$, plastic limit $\mathrm{W}_{\mathrm{P}}=30 \%$, activity $\mathrm{A}=0.36$ ). The dry soil powder was mixed with distilled water and the samples were statically compacted targeting an initial void ratio of $e_{0}=1.03$, corresponding to full saturation. The specimens were then loaded in oedometer conditions up to two different vertical effective stresses $\left(\sigma_{\mathrm{v}}{ }_{\mathrm{v}}=30 \mathrm{kPa}\right.$ for test $\mathrm{C} 1$ and $\sigma_{\mathrm{v}}=77 \mathrm{kPa}$ for test $\mathrm{C} 2$ ). They were then exposed to a saturated $\mathrm{NaCl}$ solution at constant vertical effective stress. Positive (compressive) volumetric strains occurred as the salt diffused within the samples. Afterwards, the vertical stress was increased again with the saturated $\mathrm{NaCl}$ solution as pore fluid up to a maximum stress $\sigma_{\mathrm{v}}=1 \mathrm{MPa}$, when unloading was finally performed.

In these simulations, elastic and elasto-plastic compressibility has been considered independent on osmotic suction, i.e. $\lambda_{c}=\lambda_{0}$. Table 1 provides the values of the model parameters, which were calibrated to adequately reproduce test $\mathrm{C} 1$.

Table 1. Parameters and initial value of p' 0 used in the simulation of the tests in [8].

\begin{tabular}{|c|c|c|c|c|c|c|c|}
\hline $\begin{array}{c}\kappa \\
(-)\end{array}$ & $\begin{array}{c}\mathrm{G} \\
(\mathrm{MPa})\end{array}$ & $\begin{array}{c}\lambda \\
(-)\end{array}$ & $\begin{array}{c}\mathrm{M} \\
(-)\end{array}$ & $\begin{array}{c}\mathrm{N}_{0} \\
(-)\end{array}$ & $\begin{array}{c}\mathrm{N}_{\mathrm{c}}{ }^{(*)} \\
(-)\end{array}$ & $\begin{array}{c}\kappa_{\pi} \\
(-)\end{array}$ & $\begin{array}{c}\mathrm{p}_{0} \\
(\mathrm{kPa})\end{array}$ \\
\hline 0.006 & 67 & 0.06 & 0.98 & 1.95 & 1.96 & 0.0016 & 45 \\
\hline
\end{tabular}

These tests had been simulated previously $[8,16]$ using other models, which also introduce osmotic suction as a further variable in the yield function of the Cam Clay model. However, differently from the present model, they assume that yield stress decreases with osmotic suction.

A comparison between the predictions of the present model, the experimental results and the predictions of [8] is presented in the Figures 3 and 4.

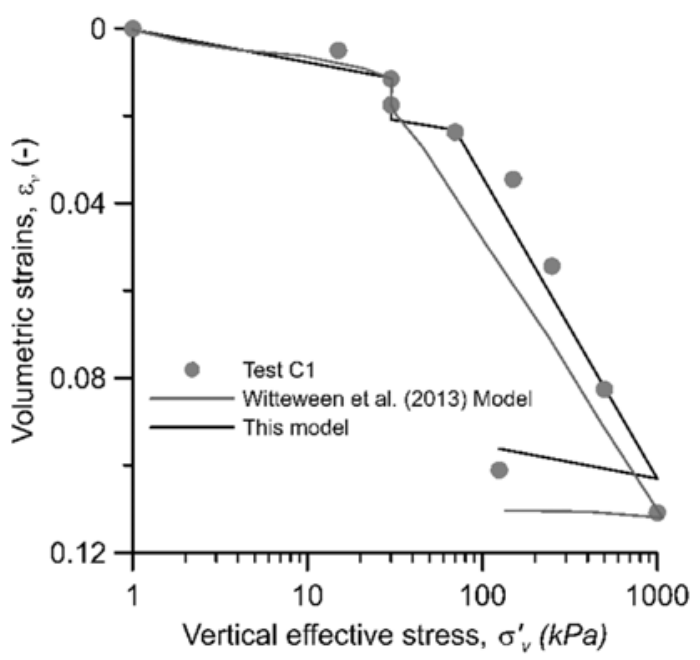

Fig. 3. Chemo mechanical behaviour of an illitic clay [8]: test $\mathrm{C} 1$ results and model predictions 


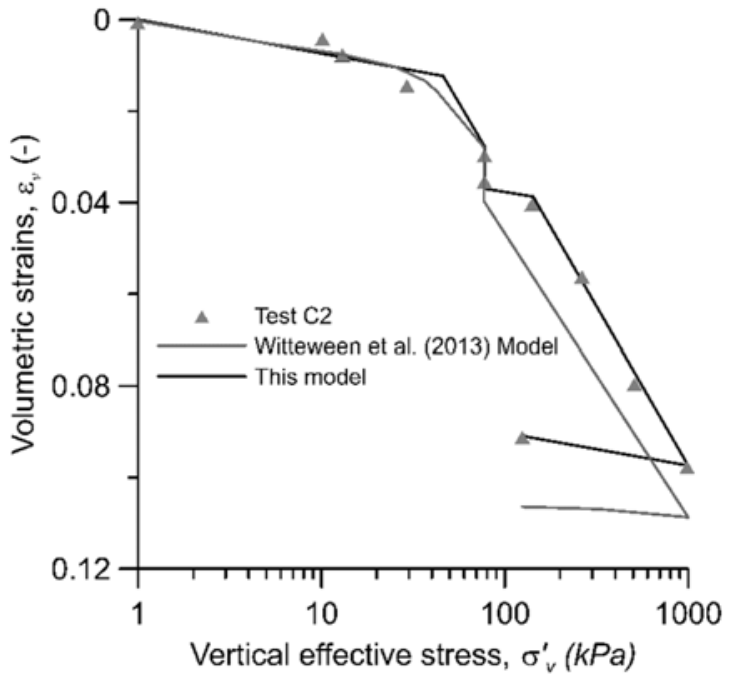

Fig. 4. Chemo mechanical behaviour of an illitic clay [8]: test $\mathrm{C} 2$ results and model predictions.

The model allows a very good reproduction of experimental data. The prediction of the volume change induced by an increase in $\pi$ at constant effective stress is satisfactory: the 'chemical strain' is very similar in the two tests, notwithstanding the different applied stress, and it is adequately reproduced by introducing a single mechanical parameter $\mathrm{k}_{\pi}$. The model is also able to predict the stiffer (elastic) response of the specimen when loaded after an increase in osmotic suction. The specimen yields at a stress larger than the maximum one applied in the previous loading history (i.e. $140 \mathrm{kPa}$ in test $\mathrm{C} 2$, Figure 4). This higher yield stress has been called 'quasi preconsolidation stress' in the literature $[7,11]$ and it provides here an apparent over-consolidation ratio $\mathrm{OCR} \cong 2$. This preconsolidation is associated to an increase in osmotic suction, and it is accounted by the model through equation (8). Such phenomenon is not reproduced by the models in $[8,16]$ which assume that $p{ }_{c}<p{ }^{\prime}$ for any value of osmotic suction. This assumption is borrowed from models formulated for highly active clays $[13,14,15]$ and it seems not to be adequate for not active clays.

\subsection{Mechanical test with osmotic suction decrease under constant stress}

The repulsive electrostatic forces between charged clay particles are inversely related to the ionic concentration of the pore fluid. Therefore, one would expect soil shrinkage when osmotic suction increases and swelling when osmotic suction decreases. Experimental results consistently confirm that volume always decreases upon salinization; vice versa desalinisation processes have been found to induce both negative and positive volumetric strains depending on previous mechanical history [7]. In particular, exposure to distilled water of samples originally saturated with a saline fluid has been found to cause swelling of high OCR samples, whereas volumetric collapse (volume reduction) has been registered on normally-consolidated or small OCR samples.
To check model capabilities to reproduce the collapse induced by desalinization, the model was used to simulate the tests conducted on remoulded Vaterland clay samples, presented in [7]. Vaterland clay is a Norwegian clay, with $\mathrm{W}_{\mathrm{L}}=40 \%, \mathrm{WP}_{\mathrm{P}}=24 \%$ and $A=0.40$. Samples were remolded with a $\mathrm{NaCl}$ solution of concentration $\mathrm{c}=26 \mathrm{~g} / \mathrm{L}(\pi=2021 \mathrm{kPa})$ as saturating solution. They were then loaded in oedometer in chemical equilibrium with the same solution to a vertical effective stress $\sigma_{\mathrm{v}}=17 \mathrm{kPa}$, and then unloaded to $\sigma_{\mathrm{v}}{ }=6 \mathrm{kPa}$. Under this stress, one specimen was exposed to distilled water and slowly collapsed ('leached test' according to the description in [7]), while the other one was left to rest without inducing pore fluid chemistry changes for the same period of time ('unleached test'). Both specimens were finally loaded to $\sigma_{\mathrm{v}}^{\prime}=160 \mathrm{kPa}$, one being in equilibrium with the distilled water and the other with the salt solution. A preliminary simulation of these tests was done adopting the parameters in Table 2. Model predictions are compared to experimental results in Figure 5.

Table 2. Parameters and initial value of p' 0 used in the simulation of the desalinisation test of Vaterland clay from [7]

\begin{tabular}{|c|c|c|c|c|c|c|c|}
\hline $\begin{array}{c}\kappa \\
(-)\end{array}$ & $\begin{array}{c}v \\
(-)\end{array}$ & $\begin{array}{c}\lambda \\
(-)\end{array}$ & $\begin{array}{c}\mathrm{M} \\
(-)\end{array}$ & $\begin{array}{c}\mathrm{N}_{0} \\
(-)\end{array}$ & $\begin{array}{c}\mathrm{N}_{\mathrm{c}}{ }^{(*)} \\
(-)\end{array}$ & $\begin{array}{c}\kappa \pi \\
(-)\end{array}$ & $\begin{array}{c}\mathrm{p}^{\prime} \\
(\mathrm{kPa})\end{array}$ \\
\hline 0.015 & 0.3 & 0.085 & 0.98 & 2.1 & 2.4 & 0.001 & 0.1 \\
\hline${ }^{(*)} \mathrm{N}_{\mathrm{c}}$ value for $\pi=2021 \mathrm{kPa}$
\end{tabular}

Very interestingly, the specimen not exposed to desalinisation kept memory of the previous loading history and it yielded at a vertical stress only slightly larger than $\sigma_{\mathrm{v}}=17 \mathrm{kPa}$, value predicted by the model. The small difference in preconsolidation pressure is probably the consequence of some ageing. The specimen exposed to desalinisation, instead, after experiencing the collapse did not keep memory of the previous mechanical loading, and practically behaved as a normallyconsolidated specimen. The model reproduces quite well the experimental results. For the sake of simplicity, it was chosen to consider the elasto-plastic compliance independent of pore fluid chemistry, although experimental data seem to suggest that distilled water NCL is somehow flatter than the one corresponding to the saline solution. Introducing such dependency would have improved the quality of the simulations, in spite of the increased number of material parameters

\section{Conclusions}

Although the sensitivity of clays to pore fluid chemistry generally increases with their activity, chemical loads still might have an impact on the mechanical behaviour of non - active clays. In particular, ionic concentration (osmotic suction) changes occurring at constant stress conditions cause volume strains. While an increase in osmotic suction always causes some shrinkage, a decrease in osmotic suction might either induce swelling or shrinkage (collapse), depending on the soil apparent OCR. The apparent OCR also increases when the osmotic suction is increased. 
A simple model, formulated in the context on the theory of elasto-plasticity with generalized hardening, is here proposed. The model is based on physical evidences of the processes triggered by osmotic changes, and specifically on the influence that the osmotic suction has on the Normal Compression Line of the soil. The model predictions compare very well to experimental results from the literature. In particular, the increase of the OCR with osmotic suction is explained in terms of the shape of the yield function, which increases with $\pi$ in the $\left(p^{\prime}, \pi\right)$ plane, whereas the shrinkage caused by desalinisation (suction decrease) at Normally Consolidated conditions is explained in terms of a plastic collapse due to a plastic process of volumetric hardening.

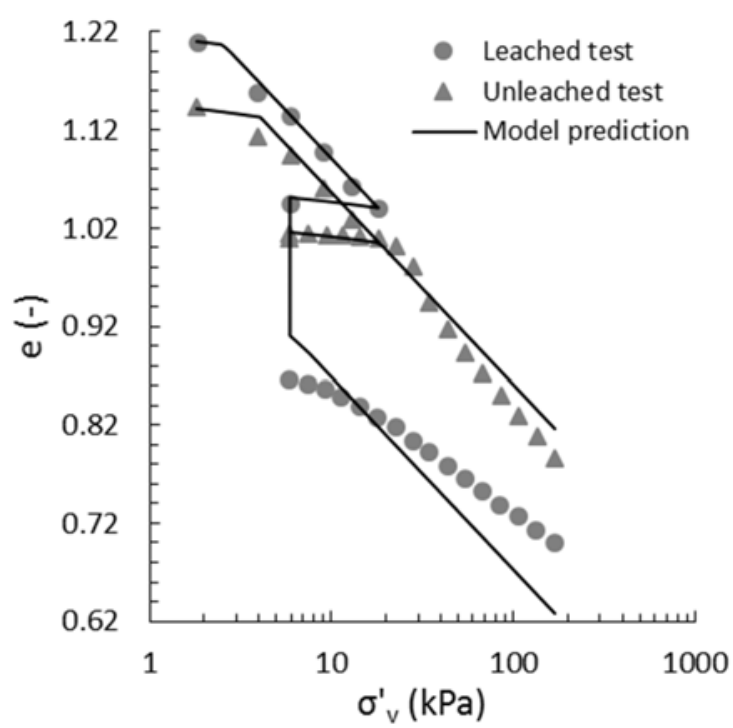

Fig. 5. Chemo mechanical behaviour of a remoulded Vaterland clay [7] exposed to desalinisation: test results and model predictions.

Acknowledgments The contribution of Marco Amato, M.Sc., in running the simulations of Vaterland clay is warmly acknowledged.

\section{References}

1. J. K. Mitchell, K. Soga Fundamentals of Soil Behavior, John Wiley and Sons, Hoboken (2005)

2. J. Jang, J. C. Santamarina, Fines Classification Based on Sensitivity to Pore Fluid Chemistry, J. Geotech. Geoenviron. Eng., 142(4), 06015018, (2016)

3. C. Di Maio, Exposure of Bentonites to Salt Solution: Osmotic and Mechanical Effects, Géotechnique, 46(4), 695 - 707, (1996)

4. E. Castellanos, M.V. Villar, E. Romero, A. Lloret, A. Gens, Chemical impact on the hydro-mechanical behavior of high-density FEBEX bentonite, Physics and Chemistry of the Earth, 33, S516-S526, (2008)

5. G. Musso, E. Romero, G. Della Vecchia, Doublestructure effects on the chemo-hydro-mechanical behaviour of a compacted active clay, Géotechnique, 63(3), 206-220, (2013)

6. J. Chen, A. Anandarajah, H. Inyang, Pore Fluid Properties and Compressibility of Kaolinite, J. Geotech. Geoenviron. Eng., 126(9), 798 - 807, (2000)

7. J. K. Torrance, A laboratory investigation on the effect of leaching on the compressibility and shear strength of Norwegian marine clays, Géotechnique, 24(2), 155-173, (1974)

8. P. Witteveen, A. Ferrari, L. Laloui, An experimental and constitutive investigation on the chemomechanical behaviour of a clay, Géotechnique, 63(3), $244-255,(2013)$

9. C. Di Maio, L. Santoli, P. Schiavone, Volume change behaviour of clays: the influence of mineral composition, pore fluid composition and stress state, Mechanics of Materials, 36, 435-451, (2004)

10. G. Musso, S. Chighini, E. Romero, Mechanical sensitivity to hydrochemical processes of Monastero Bormida clay, Water Resources Research, 44, doi:10.1029/2007WR006533 (2008)

11. L. Bjerrum, Engineering geology of Norwegian Normally-Consolidated marine clays as related to settlement of buildings, Géotechnique, 17, 81-118, (1967)

12. I.T. Rosenqvist, Considerations on the Sensitivity of Norwegian Quick-Clays, Géotechnique, 3, 195-200, (1953)

13. T. Hueckel, Chemo-plasticity of Clays Subjected to Stress and Flow of a Single Contaminant, Int. J. for Num. and An. Meth. in Geomech., 21, 43- 72, (1997)

14. B. Loret, T. Hueckel, A. Gajo, Chemo-mechanical coupling in saturated porous media: elastic-plastic behaviour of homoionic expansive clays, Int. J. of Solids and Structures, 39(10), 2773-2806, (2002)

15. L. Do N. Guimaraes, A. Gens, M. Sanchez, S. Olivella, A chemo-mechanical constitutive model accounting for cation exchange in expansive clays, Géotechnique, 63(3), 221-234, (2013)

16. R. Yan, Int. J. of Geomech. BBM-Type Constitutive Model for Coupled Chemomechanical Behavior of Saturated Soils, 18(10), 06018023 ,(2018)

17. C. Tamagnini, M. Ciantia, Plasticity with generalized hardening: constitutive modeling and computational aspects, Acta Geotechnica 11, 595-623, (2016)

18. E. E. Alonso, A. Gens, A. Josa. A constitutive model for partially saturated soils, Géotechnique $\mathbf{4 0}$ (3),405-430, (1990)

19. J.P. Bardet, W. Choucair, A linearized integration technique for incremental constitutive equations, Int. J. for Num. and An. Meth. in Geomech., 15(1), 1-19 (1991)

20. F. Cattaneo, G. Della Vecchia, C. Jommi, Evaluation of numerical stress-point algorithms on elasticplastic models for unsaturated soils with hardening dependent on the degree of saturation, Computers and Geotechnics, 55, 404-415 (2014) 